\title{
ESPONDILODISCITE CERVICAL ESPONTÂNEA CAUSADA POR Salmonella typhi EM PACIENTE IMUNOCOM PETENTE
}

\author{
Asdrubal Falavigna ${ }^{1}$, Fernando Antonio Patriani Ferraz ${ }^{2}$
}

\begin{abstract}
RESUMO - Relatamos um caso de espondilodiscite cervical espontânea por Salmonella typhi. Trata-se de um paciente de 52 anos, hígido previamente, que procurou o senviço de neurocirurgia com queixa de dor na coluna cervical e região escapular. A investigação radiológica com cintilografia óssea e ressonância magnética sugeriram processo inflamatório dos corpos vertebrais de C5-C6 e do disco vertebral interposto. Houve crescimento da Salmonella typhi na hemocultura e no material obtido pela biópsia com agulha de C5 e aumento dos títulos séricos para Salmonella typhi. O tratamento instituído foi imobilização externa com halocolete e antibioticoterapia com ciprofloxacina. Realizou-se revisão da literatura sobre aspectos clínicos, diagnósticos e terapêuticos dessa entidade de incidência incomun, principalmente pelo fato de acometer paciente imunocompetente e se localizar na região cervical da coluna vertebral.
\end{abstract}

PALAVRAS-CHAVE: espondilodiscite cervical, Salmonella typhi.

\begin{abstract}
Immunocompetent patient with spontaneous cervical spondylodiscitis caused by Salmonella typhi
ABSTRACT - We report a case of spontaneous cervical spondylodiscitis caused by Salmonella typhi. A 52-yearold man presented in the neurosurgical service with complaints of pain in the cervical and scapular region. Cervical inflammatory disease was suggested by bone scintigraphy and magnetic resonance imaging. The diagnosis of Salmonella typhi spondylodiscitis was established by blood culture and culture of needle biopsy specimen taken from the C5 vertebra. The agglutinin titers for Salmonella were elevated. Intravenous ciprofloxacin therapy and external immobilization with a halo vest were instituted. A review of literature was performed evaluating the clinical, diagnostic and therapeutic aspects of this unusual pathology.
\end{abstract}

KEY WORDS: cervical spondylodiscitis, Salmonella typhi.

A osteomielite causada por bactérias entéricas do tipo Salmonella spp é rara, ocorrendo em $0,5 \%$ dos casos $^{1}$. Habitualmente, a infecção por Salmonella está associada a anemia falciforme, imunoglobulinopatias e estados de imunossupressão ${ }^{2,3}$. O acometimento infeccioso por Salmonella na coluna vertebral é ainda mais raro, havendo 46 casos descritos na literatura ${ }^{4}$. Qualquer segmento da coluna vertebral pode ser envolvido; entretanto, a maioria dos casos ocorre na região lombar seguida pela torácica, sendo pouco frequente o acometimento da região cervical $^{5-9}$. A despeito do incremento das técnicas diagnósticas, da terapêutica e do próprio conhecimento das doenças infecciosas nos últimos anos, a espondilodiscite representa uma doença que ainda pode gerar consequências devastadoras ${ }^{5,10}$.
O objetivo deste relato é alertar sobre a necessidade de adequada e persistente avaliação radiológica e laboratorial nos processos álgicos da coluna vertebral e, na suspeita de processo inflamatório, da importância do seu diagnóstico etiológico, já que organismos dos mais variados tipos podem desencadear a doença.

\section{CASO}

Paciente de 52 anos, 78 kg, branco, masculino, casado, procurou aux́lio médico referindo dor do tipo latejante, de início súbito, localizada na região cervical e escapular e com irradiação para membros superiores. Referiu ter executado exercícios físicos prolongados dois dias antes do início dos sintomas. Não existia história de infecção respiratória alta, gastrenterite, adição a drogas, trauma

\footnotetext{
1Professor da Disciplina de Neurologia da Fundação Universidade de Caxias do Sul, Caxias do Sul RS, Brasil, Pós-graduando em Neurocirurgia na Escola Paulista de Medicina - Universidade Federal de São Paulo (EPM - UNIFESP) São Paulo SP, Brasil; ${ }^{2}$ Professor Adjunto da Disciplina de Neurocirurgia do Departamento de Neurologia e Neurocirurgia da EPM - UNIFESP, Coordenador do Programa de Pós-Graduação em Neurocirurgia.
}

Recebido 22 Fevereiro 2002, recebido na forma final 24 Maio 2002. Aceito 8 Junho 2002. 
local ou procedimentos cirúrgicos e dentários prévios. Realizou investigação com raios-X simples de coluna cervical nesse período, com resultado normal. Foram recomendados fisioterapia e uso de analgésicos e antiinflamatórios comuns, sem alívio do quadro álgico. Após seis semanas de tratamento, realizou nova consulta médica devido a exacerbação do fenômeno doloroso. Os exames físico e neurológico encontravam-se normais, exceto pela presença de espasmo muscular paravertebral. Não havia relato de aumento da temperatura corporal. Os exames séricos de hemograma, eletrólitos, TP, KTTP, creatinina efunção hepática apresentaram-se normais, com exceção da velocidade de sedimentação globular (VSG) e da proteína C-reativa (PCR) que se mostravam elevados, com valores de $84 \mathrm{~mm}$

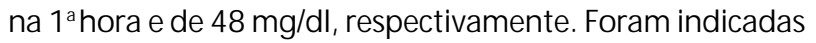
investigações com cintilografia óssea com tecnécio 99m e ressonância magnética (RM) da coluna cenvical. O exame cintilográfico evidenciou impregnação da quinta (C5) e sexta vértebra cervical (C6) (Fig 1), enquanto o de RM mostrou aumento de intensidade em T2-weighted e contrastação dos corpos vertebrais de C5 e C6 após uso intravenoso do gadolenio, acompanhado de compressão do saco dural nesses níveis e intumescimento dos tecidos moles paravertebrais adjacentes (Fig 2A). Ambos os exames sugeriam processo infeccioso da coluna cervical, cuja investigação etiológica foi realizada através de hemocultura, urocultura e biópsia fechada do corpo vertebral de C5.

A biópsia foi efetuada com o paciente em posição supina e a cabeça rotada contralateralmente. Foi introduzida a agulha na borda posterior do músculo esternocleidomastóideo, tendo sido seu trajeto e o sítio de coleta do material monitorizados constantemente através de radioscopia (ântero-posterior e perfil). Houve crescimento de Salmonella typhi na hemocultura e no material da biópsia vertebral. Foi solicitada reação de aglutinação direta destinada a avaliar anticorpos contra os antígenos $\mathrm{O}$ (somáticos) e H (flagelares) da Salmonella typhi, cujos títulos estavam elevados em valores de 1:640 e 1:160, respectivamente. Investigações posteriores não demonstraram evidência hematológica e sorológica de imunosupressão. A eletroforese da hemoglobina foi normal.

Instituiu-se antibioticoterapia intravenosa com ciprofloxacina na dose de $400 \mathrm{mg}$ a cada 12 horas, durante 6 semanas e, posteriormente, por via oral, na dose de 500 $\mathrm{mg}$ a cada 12 horas, durante mais 6 semanas. Concomitante ao uso do antibiótico foi realizada imobilização externa com halo-colete por 3 meses, seguido do uso de colar cervical de Philadelphia por 30 dias. A regressão do VSG foi de $84 \mathrm{~mm} / \mathrm{h}$, na baixa hospitalar, para $30 \mathrm{~mm} / \mathrm{h}$, após 3 semanas de antibioticoterapia intravenosa e para $2 \mathrm{~mm} /$ h, no final do tratamento antibioticoterápico. Da mesma forma, os decréscimos dos valores da PCR foram de 48, 21 e $12 \mathrm{mg} / \mathrm{dl}$ nas mesmas datas. Após 4 semanas de tratamento, a titulação dos antígenos $\mathrm{O}$ e $\mathrm{H}$ foram, respectivamente, 1:80 e zero. Uma nova RM de coluna cenvical realizada após 3 meses do início do tratamento evidenciou remissão do processo infeccioso (Fig 2B). O paciente apresentou-se assintomático após 3 anos de tratamento.

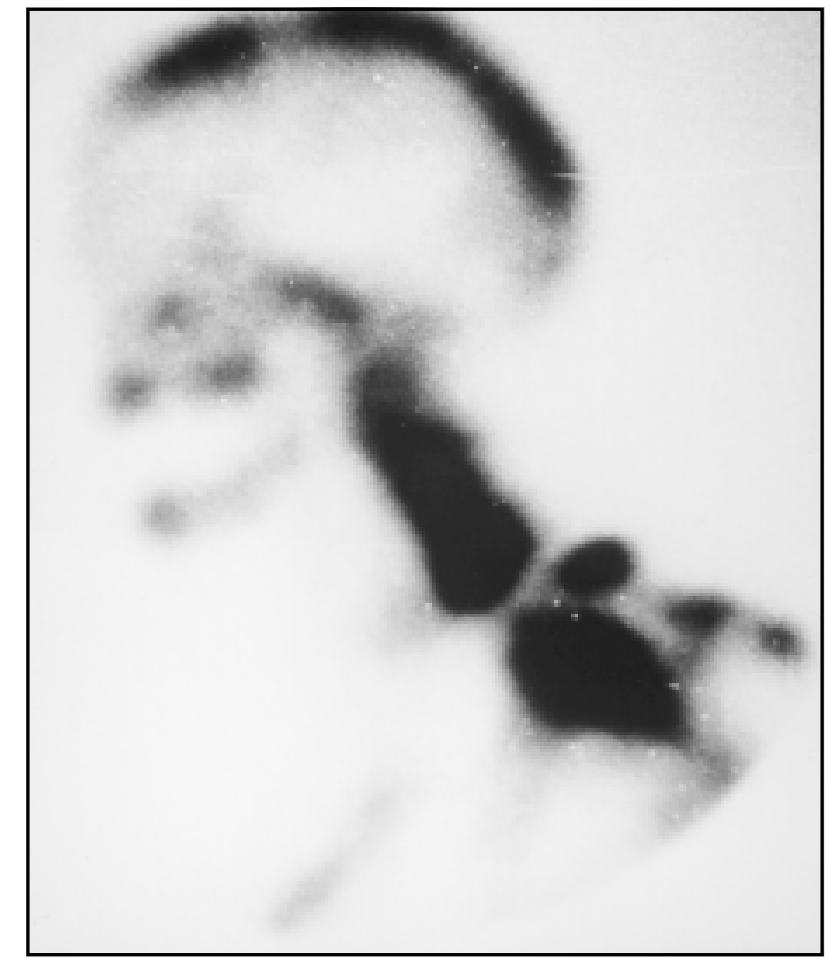

Fig 1. Cintilografia óssea com hipercaptação de C5-C6.

\section{DISCUSSÃO}

A espondilodiscite por Salmonella é rara, sendo relatados 46 casos na literatura. A salmonelose vertebral é mais comumente encontrada em pacientes com anemia falciforme, hemoglobinopatias e imunodeprimidos ${ }^{2,3}$. A distribuição de idade é bimodal, ocorrendo maior incidência na primeira e sexta décadas $^{4}$. Existe o predomínio de acometimento no sexo masculino na proporção de 1,7:14,5,8,11,12. Dos 46 casos descritos de espondilodiscite por Salmonella, a região lombar foi o local mais frequente, em $50 \%$ dos casos, seguida pela região torácica, na percentagem de $20 \%$, sendo descrito somente 1 caso na região cervical ${ }^{4-8}$. A contaminação acontece por via hematogênica, tanto arterial como venosa, pelo plexo venoso de Batson, a partir de foco de infecção à distância ou por contiguidade ${ }^{5,10}$. Em alguns casos existe a suspeita clínica de infecção prévia por Salmonella; entretanto, como foi demonstrado pelo caso aqui relatado, a espondilodiscite por Salmonella pode ser a primeira manifestação da doença ${ }^{1,13}$.

A apresentação clínica da espondilodiscite por Salmonella pode ser aguda, subaguda ou crônica ${ }^{4}$. Sapico e Montgomerie ${ }^{14}$ relataram que $50 \%$ dos pacientes apresentavam sintomas por mais de 3 meses antes de procurar auxílio médico, sendo que apenas $20 \%$ consultaram nas primeiras 3 semanas de sintomatologia. O sintoma inicial mais comum é dor lo- 


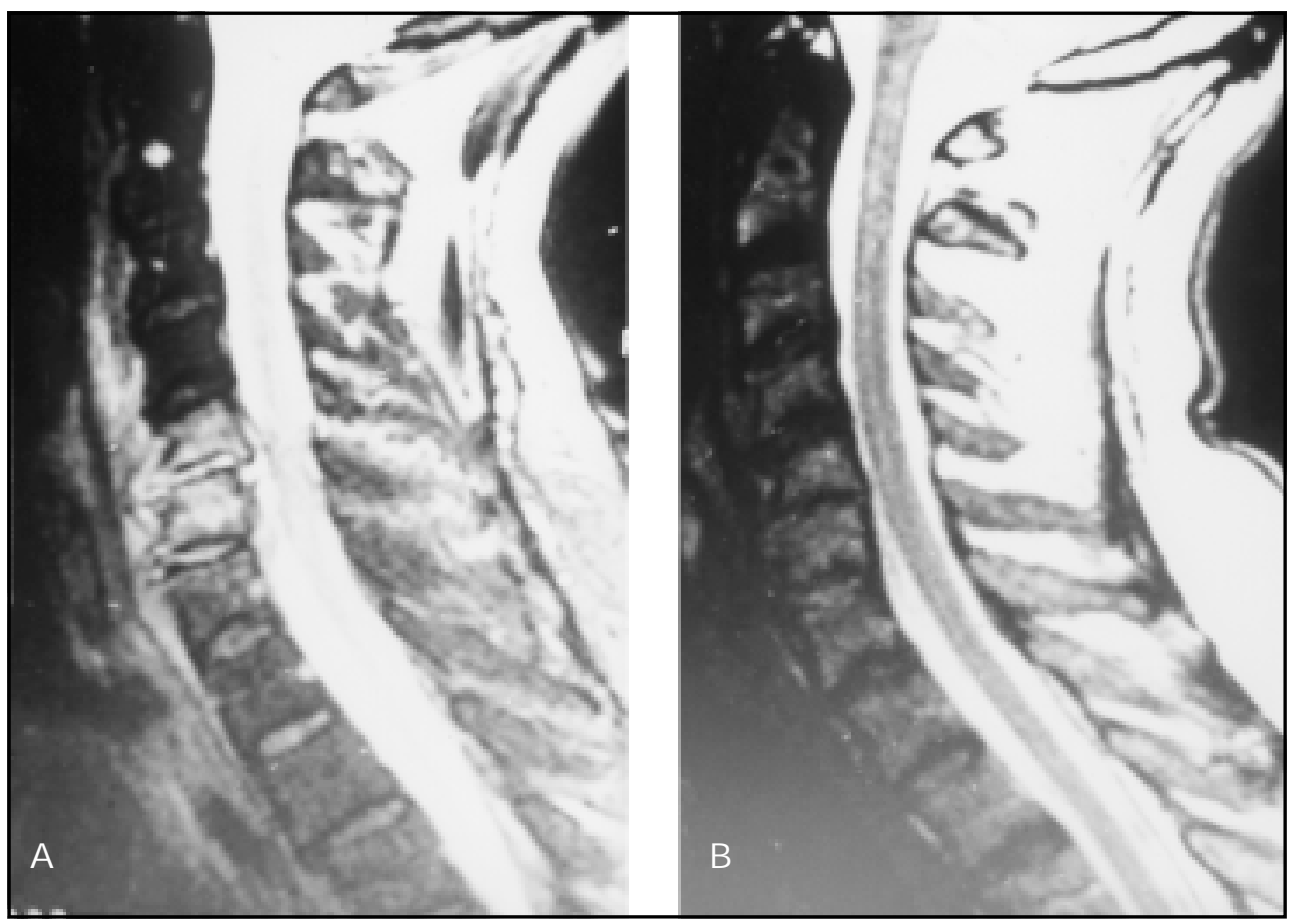

Fig 2. Ressonância magnética da coluna cervical T2-weighted com gadolineo demonstrando hiperintensidade e aumento da impregnação de C5-C6 (2A) e remissão do quadro inflamatório após três meses de tratamento (2B).

cal em $92 \%$ dos casos, seguido pela hipertermia em $87 \%$ dos pacientes 4 .

No diagnóstico por imagem, deve-se estar ciente de que, na fase inicial da doença ( 2 a 4 semanas), a radiografia convencional de coluna vertebral geralmente não detecta as alterações secundárias da espondilodiscite - estreitamento do espaço discal, edema de partes moles e destruição ou erosão das plataformas epifisárias adjacentes. A tomografia computadorizada também não é considerada um bom exame para rastreamento das lesões, tendo, atualmente, a função de orientar o procedimento de biópsia percutânea com agulha. A cintilografia óssea com tecnécio 99m é positiva em $90 \%$ dos casos. Indiscutivelmente, a RM é o exame de sensibilidade e especificidade superior a $90 \%$, sendo capaz de demonstrar as principais complicações da doença, que são compressão medular e presença e extensão do empiema epidural ${ }^{9,10}$.

No diagnóstico laboratorial, observam-se elevação do VSG em mais de $90 \%$ dos pacientes e presença de leucocitose em $40 \%$ dos casos $^{14}$. O VSG, apesar de ser pouco sensível e inespecífico para infecções, é considerado um bom teste para rastreamento, sendo útil para avaliação da resposta ao tratamento. O nível sérico da PCR também é considerado um achado laboratorial significativo de diag- nóstico e eficácia terapêutica. Rath et al. ${ }^{15}$ avaliaram a variação da PCR em 43 pacientes com espondilodiscite e concluíram que seu aumento parece ser mais fidedigno do que o do VSG. As culturas de sangue e urina são feitas na busca do diagnóstico etiológico, principalmente para casos mais agudos. Ring e Wenger $^{16}$ encontraram crescimento de germes no sangue de $56 \%$ dos casos de espondilodiscite infecciosa, contrastando com os achados de outros autores, nos quais os germes foram isolados em $10 \%$ a $33 \%$ dos pacientes ${ }^{17,18}$. Concomitante com a solicitação de hemocultura e urocultura ou nos casos em que estas forem inconclusivas, está indicada biópsia com agulha do corpo vertebral e/ou espaço intervertebral afetado ${ }^{5,7,8,11}$. A sensibilidade da biópsia fechada varia de $61 \%$ a $83 \% 5,7,8,11$. O diagnóstico da Salmonella typhi é feito através da cultura no sangue ou do foco infectado, sendo este o único recurso de valor absoluto na identificação. A reação de aglutinação avalia a presença de anticorpos contra os antígenos flagelar e de parede da Salmonella typhi, permitindo monitorar a resposta sorológica da infecção ao tratamento instituído.

Na espondilodiscite bacteriana, as infecções causadas pelas bactérias Gram-positivas é a mais frequente, ocorrendo em torno de $70 \%$ dos casos, enquanto que às Gram-negativas representam os 30\% 
restantes. Dos germes Gram-negativos, a espondilodiscite ocasionada pela Salmonella typhi tem incidência rara ${ }^{5}$. Este fato foi comprovado pelo estudo de Perronne et al. ${ }^{11}$, os quais relataram apenas um caso de Salmonella sp e outro de Salmonella typhi em 80 casos de espondilodiscite bacteriana.

As metas do manejo terapêutico da espondilodiscite são a prevenção e a reversibilidade de possíveis lesões neurológicas, o alívio da dor, a manutenção da estabilidade da coluna vertebral, a erradicação da infecção e a prevenção de recidivas ${ }^{19}$. O controle adequado de patologias sistêmicas subjacentes como diabetes melito, desnutrição ou quadro de imunossupressão, deve receber especial atenção. A imobilização da coluna com o uso da ortose tem importância significativa na prevenção da dor, deformidade ou instabilidade da coluna vertebral. O manejo através de imobilização da coluna eantibioticoterapia intravenosa determina cura do paciente em mais de $90 \%$ dos casos de espondilodiscite ${ }^{20}$. Nos 46 casos reportados de espondilodiscite por Salmonella, a combinação do tratamento cirúrgico e antibioticoterápico foi necessária em $28 \%$ dos casos. O fato de não ter sido detectada piora do quadro neurológico e ter havido melhora laboratorial foi possível, no caso apresentado, o tratamento conservador com imobilização externa e uso de antibiótico intravenoso. Na presença de deterioração neurológica ou detecção de piora do estado infeccioso pelo exame de sangue esorológico, o tratamento conservador seria abandonado.

A escolha do antibiótico adequado dependeda de terminação do agente etiológico, pois essa informação permitirá a utilização de monoterapia mais espeć́fica para o germe em questão. Uma vez diagnosticado o agente etiológico e definida sua sensibilidade farmacológica, inicia-se a administração por via intravenosa e, posteriormente, por via oral, do antibiótico com maior capacidade de penetração óssea. Apesar da sensibilidade in vitro de outros antibióticos, a ciprofloxacina, pertencente ao grupo das quinolonas, foi escolhida pelo fato de apresentar uma adequada concentração óssea, mesmo com a administração por via oral, pela baixa concentração inibitória mínima e pela mínima concentração bactericida para Salmonella $\mathrm{spp}^{21,22}$. No caso relatado, o tratamento com antibiótico foi mantido por 12 semanas, quando os sinais e sintomas clínicos desapareceram e houve retorno à normalidade dos valores do VSG, PCR e antígenos da Salmonella typhi. Na literatura, observou-se duração média do tratamento de 60 dias nos pacientes curados de espondilodiscite por Salmonella, havendo fracasso terapêutico nos casos em que o antibiótico foi administrado por tempo insuficiente ${ }^{4}$. Isto indica que o tempo de uso do antibiótico na infecção de coluna vertebral causada por Salmonella deve ser mais prolongado do que nas causadas por outras bactérias.

Em decorrência do alto risco de comprometimento neurológico e incapacidade funcional, a espondilodiscite cenvical representa entidade que requer alto índice de suspeição para um pronto diagnóstico. O caso relatado apresentou, como queixa principal, dor na coluna vertebral de evolução de 6 semanas e espasmo na musculatura paravertebral. Apesar da localização da osteomielite na região cenvical causada pela Salmonella typhi ser incomum, sua incidência e os achados clínicos e laboratoriais estão de acordo com os da literatura. A regressão dos sintomas e a normalização dos valores da VSG, PCR e do antígeno flagelar, serviram como avaliação indireta da melhora do processo infeccioso. Os princípios terapêuticos de antibioticoterapia e imobilização foram empregados no tratamento do paciente, o que levou à obtenção da cura da patologia em questão.

\section{REFERÊNCIAS}

1. Ortiz-Neu C, Marr J, Cherubin $\mathrm{C}, \mathrm{Neu} \mathrm{H}$. Boneand joint infections due to Salmonella. J Infect Dis 1978;138:820-828.

2. Hook E. Salmonellisis: certain factors influencing the interaction of Salmonella and the human host. Bull N Y A cad Med 1961;37:499-512.

3. Givner L, Luddy R, Schwart A. Etiology of osteomyelitis in patients with major sickle hemoglobinopathies. J Pediatr 1981;99:411-413.

4. Santos E, Sapico F. Vertebral osteomyelitis due to Salmonellae: report of two cases and review. Clin Infect Dis 1998;27:287-295.

5. Staufer R. Pyogenic vertebral osteomyelitis. Orthop Clin N Am 1975;6:1015-1027.

6. Waldwogel F, Vasey H. Osteomyelitis: the past decade. N Engl J Med 1980;303:360-370.

7. Abramovitz J, Batson R, Yablon J. Vertebral osteomyelitis: the surgical management of neurological complications. Spine 1996;11:418-420.

8. Larget-Piet B, Martigny J. Bacterial spondylodiskitis: etiology, diagnosis, development, prognosis, treatment. Rev Prat 1995;45:915-920.

9. Cahill D. Pyogenic infection in thespine. In Menezes A Sonntag V (ed.) Principles of spinesurgery. Philadel phia: McGraw-Hill, 1996:1453-1466.

10. Kelly PJ. Infections of thespine. In Spinal disorders: diagnosisand treatment. RugeD, Wiltse LL (eds.). Philadelphia: Lea and Febiger, 1997:96-101.

11. Perrone C, Saba J, Behloul Z. Pyogenic and tuberculous spondylodiskitis (vertebral osteomyelitis) in 80 adult patients. Clin Infect Dis 1994;19:746-750.

12. Gomez Rodriguez N, Martinez Vasquez C, Sopeña B. Non-tuberculous spondylodiscitis. multicenter study of 19cases. Rev Clin Esp 1989,184:289-296.

13. Tsui H, Chiu K, Leung K. Osteomyelitis of the spine due to Salmonella infection - conservative treatment with quinolona: a case report. Can J Surg 1997; 40:48-50.

14. Sapico F, Montgomerie J. Pyogenic vertebral osteomyelitis: report of nine cases and review of the literature. Rev Infect Dis 1974;1:754-761.

15. Rath S, N eff U, Schneider O, Richter $\mathrm{H}$. N eurosurgical management of thoracic and lumbar vertebral osteomyelitis and discitis in adults: a review of 43 consecutive surgically treated patients. Neurosurgery 1996;38:926-933.

16. Ring $D$, Wenger $D$. Magnetic resonance-imaging scans in discitis. Sequential studies in a child who needed operative drainage: a case report. J Bone Joint Surg 1994; 76: 596-601.

17. Miller O. Doenças Infecciosas. In Miller O (ed.). Laboratório para o clínico. Rio de Janeiro: Atheneu, 1986:369-407.

18. Sapico F, Montgomerie J. Vertebral osteomyelitis. Infect Dis Clin N Am 1990;4:539-543.

19. Currier B, Heller G, Eismont F. Cervical spine infections. In Clarck C (ed.). The cervical spine. Philadelphia: Lippincott-Raven, 1998:659-690.

20. Pritchard A, Thompson W. Acute pyogenic infection of the spine in children. J Bone Joint Surg 1960;42: 86-89.

21. Fong I, Ledbetter W, Vandenbrouke A, et al. Ciprofloxacin concentrations in bone and muscle after oral dosing. Antimicrob Agents Chemother 1986;29:405-408.

22. Waldvogel $F$. Use of quinolones for the treatment of osteomyelitis and septic arthritis. Rev Infect Dis 1989; 11 (Suppl 5): S1259-1263. 